\title{
Comparison of Digital Elevation Models for Determining the Area and Volume of the Water Reservoir
}

\author{
Bakiev, M. ${ }^{1}$ and Khasanov, $\mathrm{K}^{2 *}$ \\ Hydrotechnical Construction and Engineering Structure Department, Tashkent Institute of Irrigation and \\ Agricultural Mechanization Engineers, Kari Niyaziy Str., 39, 100000, Tashkent Uzbekistan \\ E-mail: bakiev1947@ rambler.ru, ${ }^{1}$ kh.khasanov@mail.ru²*
}

\begin{abstract}
Nowadays, like many other fields, DEM is widely used in the field of hydraulic engineering. In our studies, we compared the DEMs (SRTM, ASTER GDEM v2, and ALOS PALSAR) for the area recommended for the construction of the Shurbulak water reservoir. Contours were developed for all DEMs and were compared with the contours of a topographic map. The contours of the SRTM and ALOS PALSAR closely match with the contours on the topographic map than ASTER. Vertical differences between SRTM, ASTER GDEM2, and ALOS PALSAR products were computed the root mean squared error (RMSE) compared to Ground Control Point (GCP) data. RMSE results show that $3.53 \mathrm{~m}$ for ALOS PALSAR, $6.27 \mathrm{~m}$ for ASTER and $4.09 \mathrm{~m}$ for SRTM. The longitudinal profiles of dams (No. 1 and No. 2) of all DEMs were compared with the data of the design institute - UzGIP. The results of comparing the longitudinal profile of the dam (No. 1 and No. 2) on digital ALOS PALSAR models correspond to the longitudinal profile of dams (No. 1 and No. 2) developed by the design institutes. Viewed as a result of all comparisons (comparison of DEMs and topographic map, computed RMSE, comparison longitudinal profile of the dam) ALOS PALSAR is more accurate than other DEMs. Therefore, we decided to use ALOS PALSAR for the determination of water reservoir area and volume. The area and volume of the reservoir were determined using the digital model ALOS PALSAR.
\end{abstract}

\section{Introduction}

The surface of the earth is a constant phenomenon. As we all know, there are many different ways to present surfaces digitally using many digital storage methods. Digital Elevation Model (DEM)s are one of the simplest ways of displaying topographic surfaces DEM is a quantitative model of topographic surface in digital form, any digital image of the topographic surface, and the simplest and most common form of digital topography (Burrough, 1986 and Fisher, 1996). The DEMs data set is an important source of information along with the representation of a permanent topographic surface and is usually used to represent the topographic surface in three dimensions and to simulate natural geography (Hadrian et al., 1988).

DEM data have generally formed by high-tech ground survey techniques, existing topographic maps, and interpretation of image data acquired from airborne or satellite platforms (Nelson and et all., 2009). Moreover, DEMs can be created by stereoscopy, photoclinometry, synthetic aperture radar or laser and radar altimetry methods (Komeil et al., 2015 and Ayman and Ling 2019). Nowadays, the application of remote sensing methods to extract DEMs from satellite images instead of direct measurement techniques has become a trend (Ugur, A., Baris, B. and Elif, S., 2018). Because, present- day remote sensing satellites with the capability of stereo and tri stereo imaging in addition to their high temporal and spatial resolutions, low-cost production compared to direct measurements (Barbarella et al., 2019)

However, DEMs are prone to errors, because they can never be completely eradicated, and they need to be managed effectively and investigate their errors (Nikolakopoulos et al., 2006 and Chen et al., 2016). The main reasons for the DEM errors are technical reasons: improper instrument operation, physical limitations of sensors or natural reasons: bad weather conditions, due to the low contrast of the relief, low or very high relief and like this for various reasons (Chuanfa et al., 2016 and Lei et all, 2014). Moreover, due to the altitude data acquisition methodology and the different processing stages of the models. Accuracy is an important aspect of DEM and depends on a variety of factors, such as the methods of interpolation of data sources, data density, data quality and topographic features of the surface. These factors may adversely affect some DEM-based applications that require some position errors (Qiming and Xuejun, 2004, Milan et al., 2011, James et al., 2007 and Thomas et al., 2015).

We can get global or near-global DEMs are available in several open-search databases of several 
missions. Popular of them: Shuttle Radar Topography Mission (SRTM), Advanced Spaceborne Thermal Emission Reflectometer (ASTER) onboard NASA's Terra satellite, Advanced Land Observing Satellite (ALOS) (Moritz and Christian, 2014).

SRTM - the first single-pass SAR (synthetic aperture radar) interferometer in space has been flown after some delay onboard the Space Shuttle Endeavour (STS-99) operated the modified dual antenna synthetic aperture radar systems during this 11-day in February 2000, was a joint project of the National Aeronautics and Space Administration, the National Geospatial-Intelligence Agency (NGA) (formerly National Imagery and Mapping Agency (NIMA)) of the U.S. Department of Defense (DOD) (Werner, 2001 and Rabus et al., 2003). SRTM acquired both C-band and X-Band synthetic aperture radar data set mission which allows generating a new consistent and more accurate global digital terrain model and topographic maps of all land surfaces between $+60^{\circ}$ and $-56^{\circ}$ latitudes and it has been successfully achieved. SRTM DEM data have a horizontal resolution of 1 arc-second (30 $\mathrm{m}$ at the equator) and a vertical resolution of $10 \mathrm{~m}$ (C-band radar). The data are free and in a simple format, available from the USGS or Opentolology website on a continent by continent basis (Wasilewski and Chormański, 2009 and Hensley et al., 2000).

ASTERGDEM v2 - the freely available Advanced Spaceborne Thermal Emission and Reflection Radiometer Global Digital Elevation Model Version 2 (ASTER GDEM) is a joint initiative undertaken by the Ministry of Economics, Trade and Industry (METI) of Japan and the National Aeronautical and Space Administration (NASA) of the United States, was released to the public in mid-October, 2011. Improvements within the GDEM2 result from acquiring 260,000 additional scenes to enhance coverage, a smaller correlation kernel to yield a better spatial resolution, and improved water masking. The ASTER GDEM spatial resolution lasts between $83^{\circ} \mathrm{N}$ and $83^{\circ} \mathrm{C}$ p 1 arc-second and the products useful for most applications and ASTER GDEM2 data, one of the highest-resolution DEM data collections in the world to date, we can downloaded at USGS websites (Cowan and Cooper, 2005, Tom et al., 2004-2007, Wang et al., 2012 and Tachikawa et al., 2011).

ALOS PALSAR - it means: ALOS - Advanced Land Observation System, PALSAR - Phased Array L-band Synthetic Aperture Radar. From 2006 to 2011 Japan Aerospace Exploration Agency (JAXA) launched an ALOS satellite with PALSAR radar. The ALOS $\backslash$ PALSAR data have been used by many researchers in studying the earth's surface and is still in use today for many purposes. PALSAR is an $\mathrm{L}$ band SAR and it has many modes including fine mode, scan SAR mode, and full polarimetric mode. Its recurrence is 14 days and it has the ability to get scenes in 150 scenes. PALSAR is an L band SAR and has a fine mode, scan SAR mode, and full polarimetric mode (Filatov, 2016, Clewley at al., 2016, Pierre et al., 2017 and Van et al., 2019).

\section{Materials and Methods}

Nowadays, Global Mapper one of the technologies of geographic information systems (GIS) is an integral part of many branches of industry. Using the digital elevation model (DEM) in the Global Mapper, it is possible to determine the potential location for the reservoir construction, to estimate the volume of the reservoir build-up, to simulate groundwater, to determine possible erosion and the mudflow hazard and mudflow-resistant areas (Khasanov et al., 2019). The overall purpose of this paper is to perform an accurate assessment of the free to download DEMs SRTM, ASTER GDEM v2, and ALOS PALSAR for the area of Shurbulak water reservoir, the Republic of Karakalpagistan, and to evaluate open-source DEMs (SRTM, ASTER GDEM v2, and ALOS PALSAR) by comparing a topographic map (1:50000) for the estimated location recommended for the construction of the Shurbulak water reservoir. In addition, the vertical accuracy of each DEM elevation matrix is estimated using data from the Global Positioning System (GPS) at 45 points obtained from intensive geodetic surveys.

Shurbulak water reservoir, located on the Southwest side of Uzbekistan, the Republic of Karakalpagistan, extends between the latitude of 41 deg. $\mathrm{N}$ and the longitude 61 to $62 \mathrm{deg}$. E. An area approximately $85 \mathrm{~km}$ by $30 \mathrm{~km}$, characterized by moderate to high relief with elevations from $72 \mathrm{~m}$ to $184 \mathrm{~m}$ above vertical datum. The study area consists of small hills, plains, and sandy areas and has not high elevation differences. The coordinate system is UTM zone 41 north (Figure 1). The SRTM DEM were initially referenced to the WGS84 EGM96 geoid and horizontally georeferenced to the WGS84 ellipsoid using a UTM projection, the data type is GeoTIFF, data were obtained from open-search base data Open Topography (High-Resolution Topography Data and Tools), Data Selection Coordinates: from $\mathrm{X}_{\min }=61.39, \mathrm{Y}_{\min }=41.29$, to $\mathrm{X}_{\max }=61.89, \mathrm{Y}_{\max }=41.60$ 


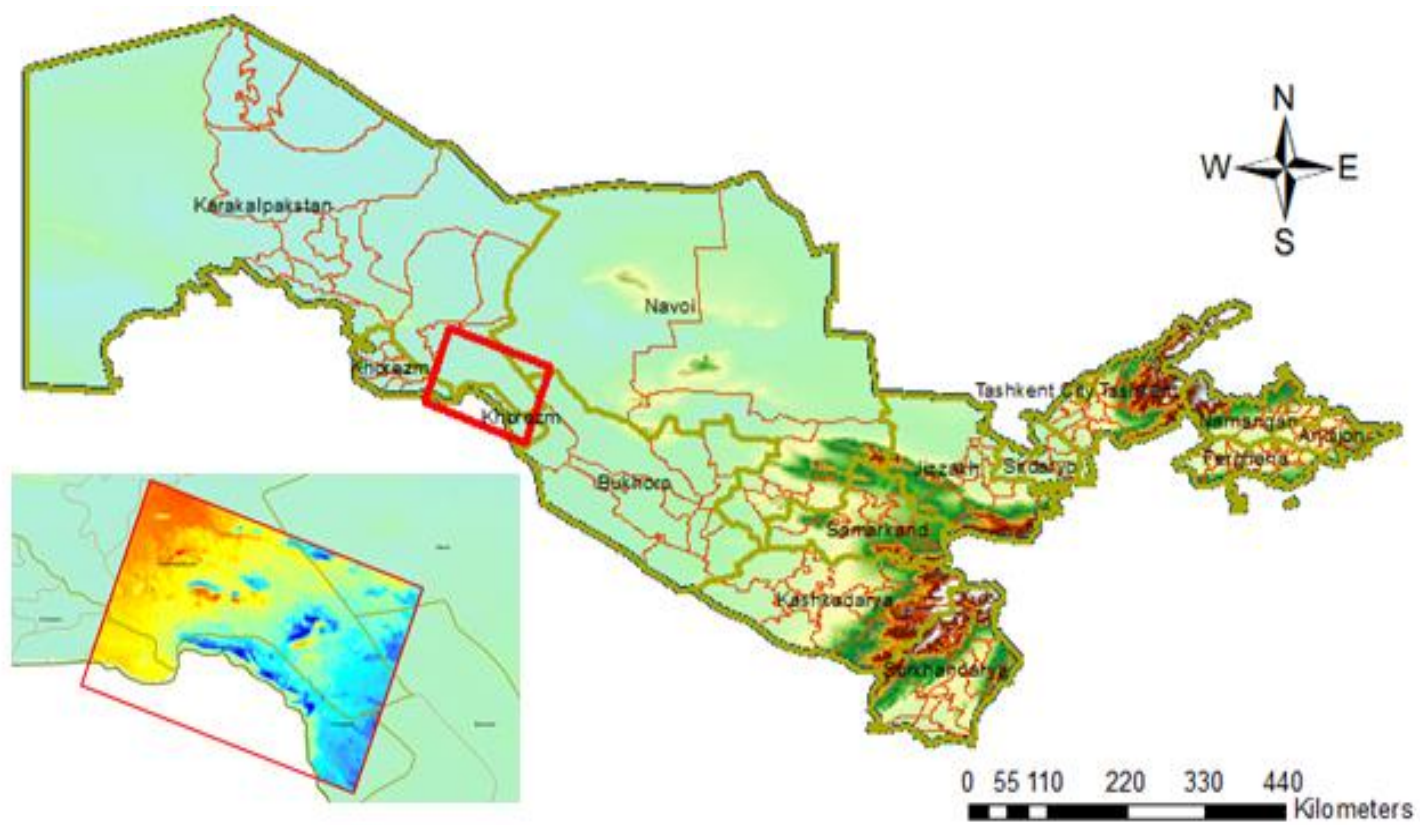

Figure 1: Location of Shurbulak water reservoir

The ASTER DEM v2 was downloaded from USGS (U.S. Geological Survey). Coordinate System UTM, Datum - World Geodetic System (WGS84), data type is GeoTIFF, Data Selection Coordinates: NW Corner Lat $41^{\circ} 53^{\prime} 59.28^{\prime \prime} \mathrm{N}$, NW Corner Long $61^{\circ} 03^{\prime} 02.52^{\prime \prime} \mathrm{E}$, NE Corner Lat $41^{\circ} 54^{\prime} 46.08^{\prime \prime} \mathrm{N}$, NE Corner Long, $62^{\circ} 05^{\prime} 27.96^{\prime \prime} \mathrm{E}$, SE Corner Lat $41^{\circ} 13^{\prime} 02.28^{\prime \prime} \mathrm{N}$, SE Corner Long $62^{\circ} 06^{\prime} 02.52^{\prime \prime} \mathrm{E}$, SW Corner Lat $41^{\circ} 12^{\prime} 16.92^{\prime \prime} \mathrm{N}$, SW Corner Long6 $1^{\circ} 04^{\prime} 17.40^{\prime \prime} \mathrm{E}$. The ALOS DEM was downloaded from Vertex (the Alaska Satellite Facility's data portal for remotely sensed imagery of the Earth). Beam mode: FBS, Path: 549, Frame: 820, Ascending/Descending: Ascending, Polarization: HH, Off Nadir Angle: $34.3^{\circ}$, Faraday rotation: $2.48^{\circ}$, Absolute Orbit: 11738 , Frequency: L-Band. All DEMs were saved in GeoTIFF format using Global Mapper - one of the GIS software and re-projected from WGS 1984 geographic coordinates system to UTM $41 \mathrm{~N}$ projection.

\section{Results and Discussion}

Topographic map and all DEMs are downloaded to Global mapper software. 120 contours were digitized on the topographic map and one by one 120 contours were also generated in DEMs for comparing with a topographic map. The results are presented in Figure 2(a, b, c, d). As shown in Figure. 2 the 120 contours of the SRTM and ALOS PALSAR closely match the contours on the topographic map than ASTER GDEM2 DEM. In this work, a data set of 45 ground control points (GCPs) measured by the GPS has been used to estimate the vertical accuracy of the DEMs. These points cover almost the entire area Figure 3. Vertical differences between SRTM, ASTER GDEM2, and ALOS PALSAR products were computed the root mean squared error (RMSE) compared to GPS data. RMSE results show that 3.53 for ALOS PALSAR, 6.27 for ASTER and 4.09 for SRTM in Figure 4(a, $\mathrm{b}, \mathrm{c}$ ). The longitudinal profiles of dams (No. 1 and No. 2) of all DEMs are compared with the data of the design institute - UzGIP. The results of comparing the longitudinal profile of the dam (No.1 and No.2) on digital ALOS PALSAR models correspond to the longitudinal profile of dams (No.1 and No.2) developed by the design institutes in Figures 4, 5 and 6.

\section{Conclusion}

In this study, we compared the DEM (SRTM, ASTER GDEM2, and ALOS PALSAR) with topographic map data (1: 50000) for the area recommended for the construction of the Shurbulak water reservoir. Viewed as a result of all comparisons (comparison of DEMs and topographic map, computed RMSE, comparison longitudinal profile of the dam) ALOS PALSAR is more accurate than other DEMs. Therefore, we decided to use ALOS PALSAR for determination of water reservoir area and volume. The area and volume of the reservoir were determined using the digital model ALOS PALSAR. The surface area was generated for a specified elevation to determine reservoir surface area and volume. 


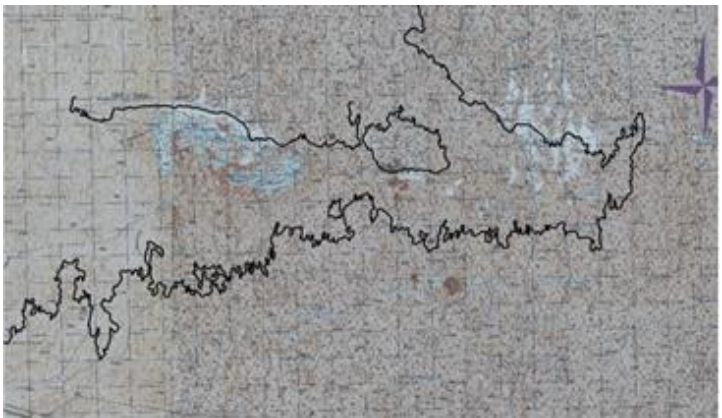

a)

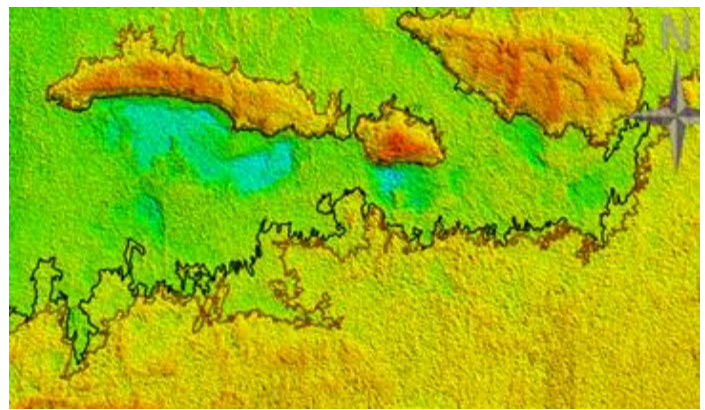

c)

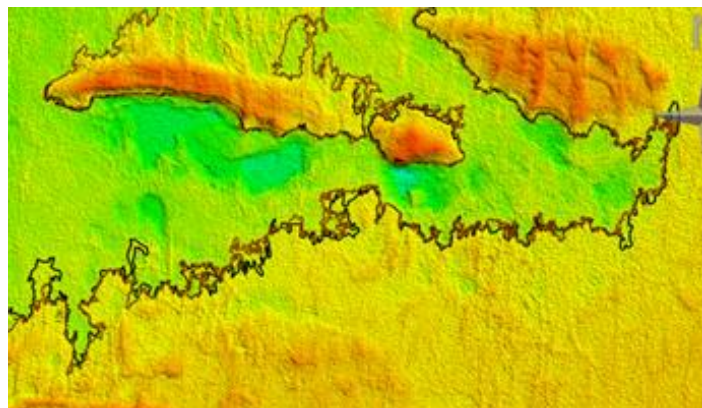

b)

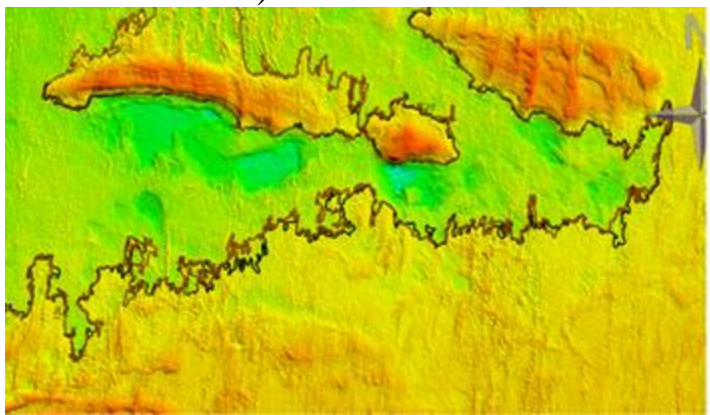

d)

Figure 2: Comparison of 120 contour (sea level), 120 contours digitized on topographic maps (a) are compared with SRTM DEM (b), ASTER GDEM v2 DEM (c), ALOS PALSAR DEM (d)

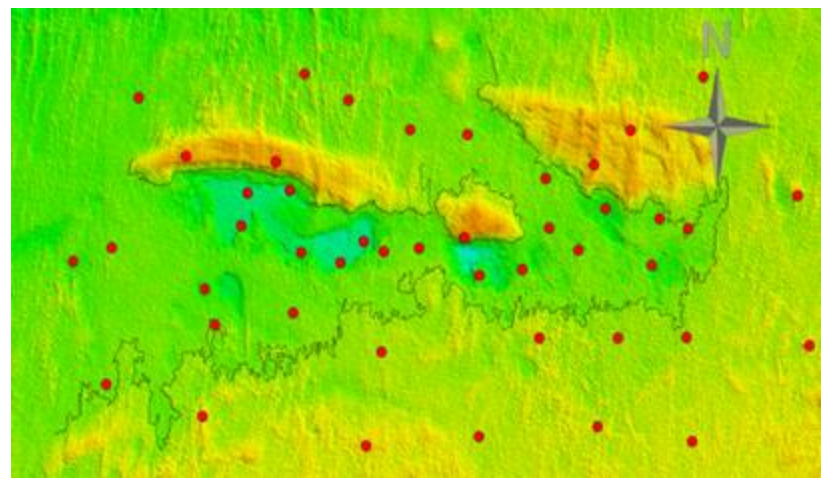

Figure 3: Ground Control Points (measured by the GPS)

by specified intervals. Summarizing them we can determine the total volume of the reservoir. The surface area was generated from this contour (117) Figure 7. There are three methods for determination of the area and volume are observed in Global Mapper. Use Same Base Height Value for All Vertices - the chosen height was entered and the area plus the volume is determined at this height. Use Height from Terrain Surface at Boundary (Measure Pile Volume) - the area and the volume is determined between the developed surface and the digital model (Khasanov, 2020). Perform Multiple Calculations over Range of Base Heights determines the area and the volume at each interval according to Step size between two heights. For instance, if we enter range between 78 and 117 with interval of 1 , then we can count up to 40 areas and volumes for the range between 78 and 117. Using Copy to Clipboard, we can transfer the data into Excel file (Table 1). In the water reservoir, the maximum water level is 117. Contour lines and surfaces (areas) are created using this software. From the existing uplands ranging from 78 to 117 $\mathrm{m}$, the dam height of $119 \mathrm{~m}$ was determined visually based on the maximum water reservoir volume and minimization of earthworks. Two sections are fount at this level, where dams N1 and N2 must be built. The software allows calculating areas and volumes. 
Root Mean Square Error: 4.098

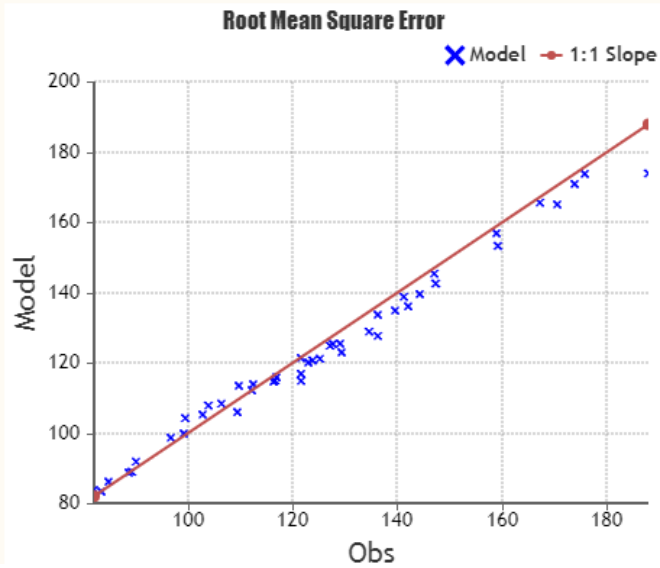

Root Mean Square Error: 6.279

Root Mean Suuare Error

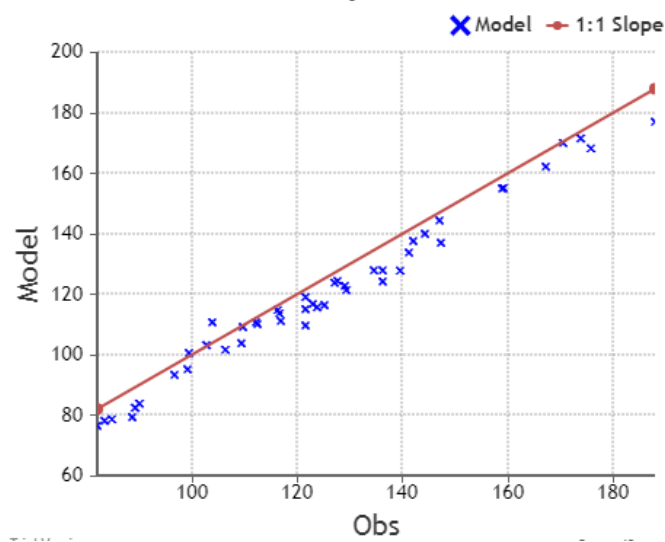

Root Mean Square Error: 3.538

Root Mean Suuare Error

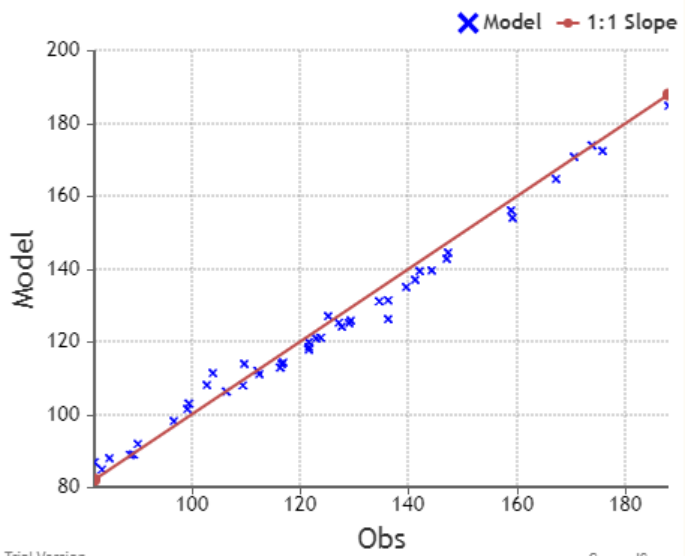

Figure 4: RMSE results. a) SRTM, b)ASTER GDEM v2, c) ALOS PALSAR

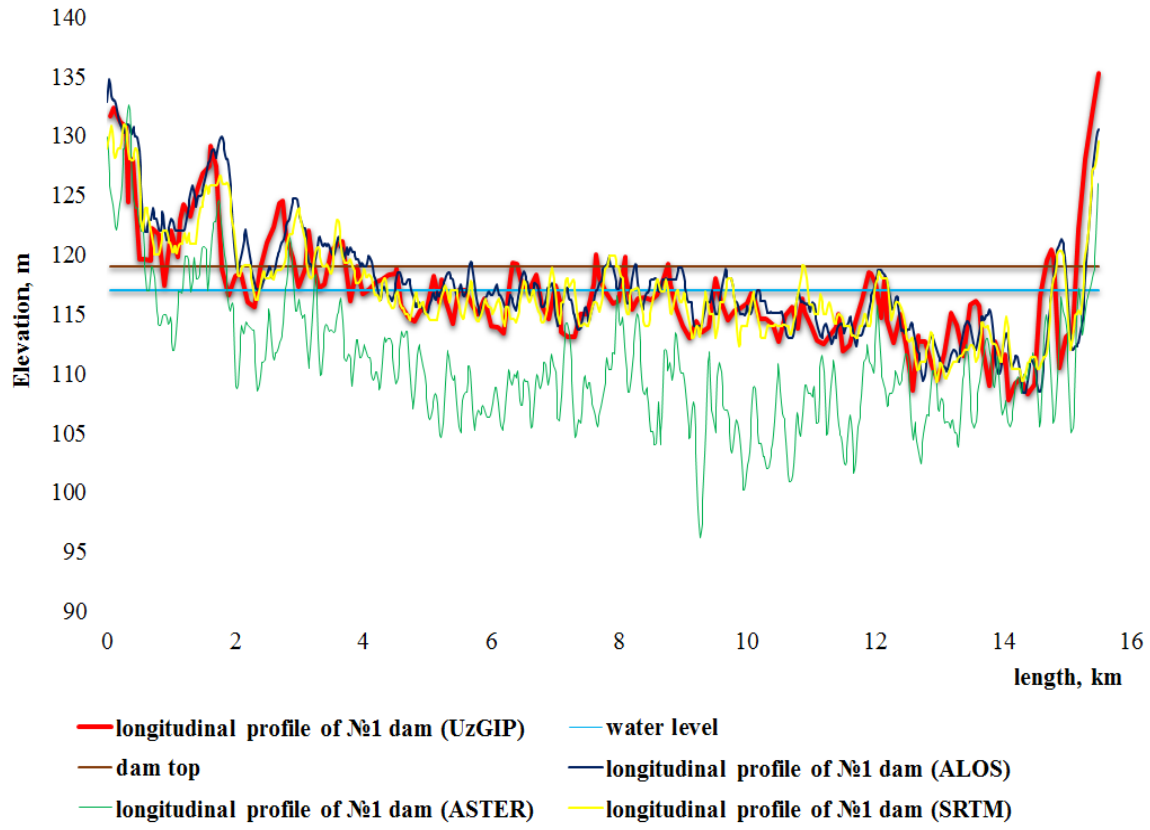

Figure 5: Longitudinal profile of dam No 1

International Journal of Geoinformatics, Volume 17, No. 1, February 2021

Online ISSN 2673-0014/ @ Geoinformatics International 


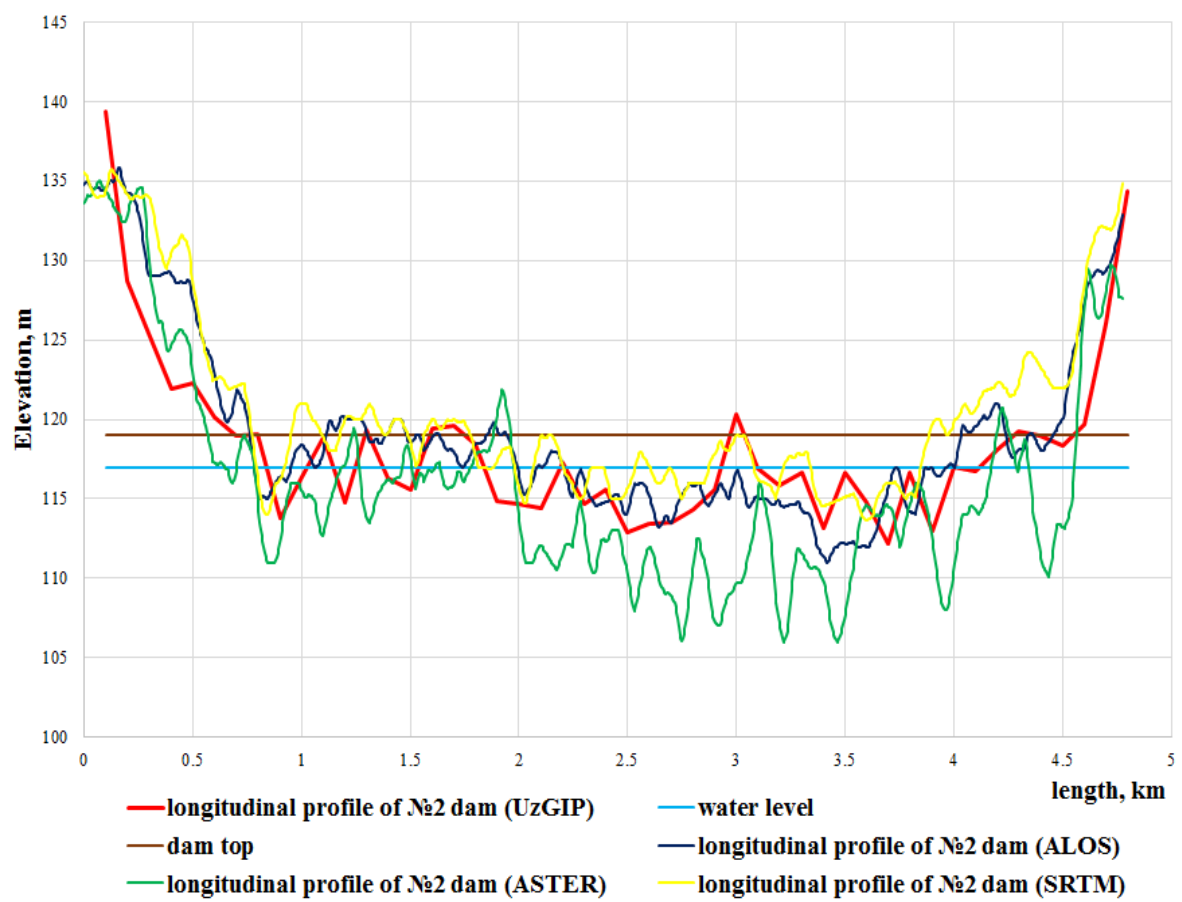

Figure 6: Longitudinal profile of dam No 2

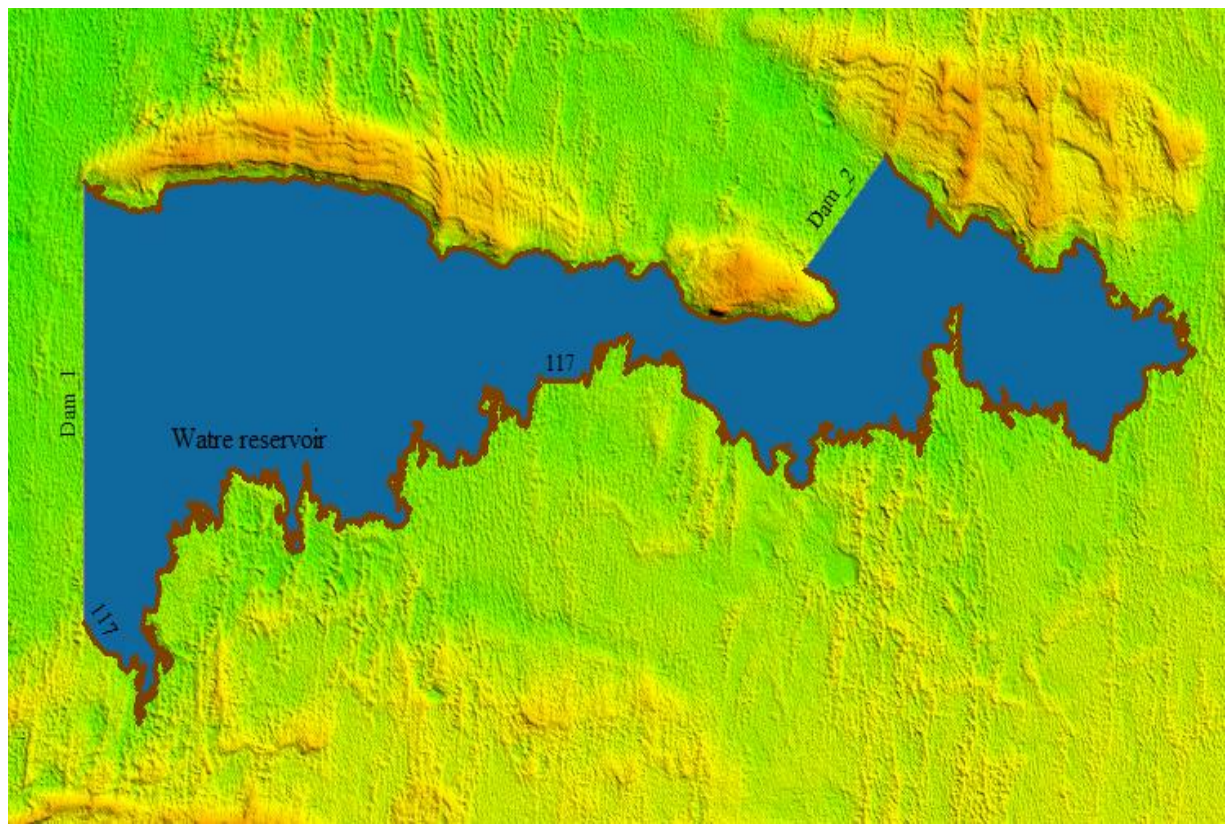

Figure 7: Water reservoir surface area

Based on the results obtained contour and volume $\mathrm{W}=\mathrm{f}(\mathrm{H})$ curves were developed. The results were compared with the data of the design institute performed using a geodetic tablet in Figure 8. All the spheres of the national economy, including the construction of hydrotechnical structures, use GIS technologies and digital data developed with the use of remote sensing. We have performed research, aimed at the use of these modern science achievements in determining the area and the volume of Shurbulak water reservoir. The practical value of the work consists of that, we compared the DEM (SRTM, ASTER GDEM2, and ALOS PALSAR) with topographic map data (1:50000) for the area recommended for the construction of the Shurbulak water reservoir and recommended the use of ALOS PALSAR DEMS in this reservoir construction. 
Table 1: Areas and volumes by contours for Shurbulak water reservoir

\begin{tabular}{|c|c|c|c|c|c|}
\hline $\begin{array}{c}\text { BASE_HEIGHT } \\
\text { (sea level) }\end{array}$ & $\begin{array}{c}\text { FILL VOLUME } \\
\mathbf{m}^{3}\end{array}$ & $\begin{array}{c}\text { FILL AREA } \\
\text { Sq. } \mathbf{~ k m} .\end{array}$ & $\begin{array}{c}\text { BASE_HEIGHT } \\
\text { (sea level) }\end{array}$ & $\begin{array}{c}\text { FILL VOLUME } \\
\mathbf{m}^{\mathbf{3}}\end{array}$ & $\begin{array}{c}\text { FILL AREA } \\
\text { Sq. } \mathbf{~ k m . ~}\end{array}$ \\
\hline $78 \mathrm{~m}$ & 422.71807 & 0.001492 & $98 \mathrm{~m}$ & 294789302 & 43.444 \\
\hline $79 \mathrm{~m}$ & 10989.37 & 0.02288 & $99 \mathrm{~m}$ & 339804126 & 46.397 \\
\hline $80 \mathrm{~m}$ & 67770.115 & 0.098 & $100 \mathrm{~m}$ & 387759912 & 49.277 \\
\hline $81 \mathrm{~m}$ & 291544.88 & 0.3282 & $101 \mathrm{~m}$ & 438571814 & 52.184 \\
\hline $82 \mathrm{~m}$ & 773512.42 & 0.597 & $102 \mathrm{~m}$ & 492491308 & 55.429 \\
\hline $83 \mathrm{~m}$ & 1534059.5 & 0.898 & $103 \mathrm{~m}$ & 550007264 & 59.287 \\
\hline $84 \mathrm{~m}$ & 2582707.8 & 1.176 & $104 \mathrm{~m}$ & 611533379 & 63.428 \\
\hline $85 \mathrm{~m}$ & 3924520.7 & 1.526 & $105 \mathrm{~m}$ & 677241972 & 67.672 \\
\hline $86 \mathrm{~m}$ & 5968079.2 & 2.529 & $106 \mathrm{~m}$ & 747236833 & 72.028 \\
\hline $87 \mathrm{~m}$ & 9601942.4 & 4.497 & $107 \mathrm{~m}$ & 821893976 & 77.035 \\
\hline $88 \mathrm{~m}$ & 15753105 & 7.484 & $108 \mathrm{~m}$ & 902039604 & 82.82 \\
\hline $89 \mathrm{~m}$ & 25971984 & 12.224 & $109 \mathrm{~m}$ & 988272283 & 89.205 \\
\hline $90 \mathrm{~m}$ & 41474698 & 17.488 & $110 \mathrm{~m}$ & 1081689982 & 97.212 \\
\hline $91 \mathrm{~m}$ & 61504565 & 21.725 & $111 \mathrm{~m}$ & 1184510910 & 107.73 \\
\hline $92 \mathrm{~m}$ & 85449698 & 25.728 & $112 \mathrm{~m}$ & 1299077343 & 120.54 \\
\hline $93 \mathrm{~m}$ & 113364124 & 29.4 & $113 \mathrm{~m}$ & 1427989255 & 136.13 \\
\hline $94 \mathrm{~m}$ & 144161270 & 31.921 & $114 \mathrm{~m}$ & 1573908378 & 154.24 \\
\hline $95 \mathrm{~m}$ & 177502377 & 34.513 & $115 \mathrm{~m}$ & 1739275927 & 174.61 \\
\hline $96 \mathrm{~m}$ & 213553600 & 37.414 & $116 \mathrm{~m}$ & 1925710118 & 196.11 \\
\hline $97 \mathrm{~m}$ & 252670797 & 40.56 & $117 \mathrm{~m}$ & 2132243697 & 214.47 \\
\hline
\end{tabular}

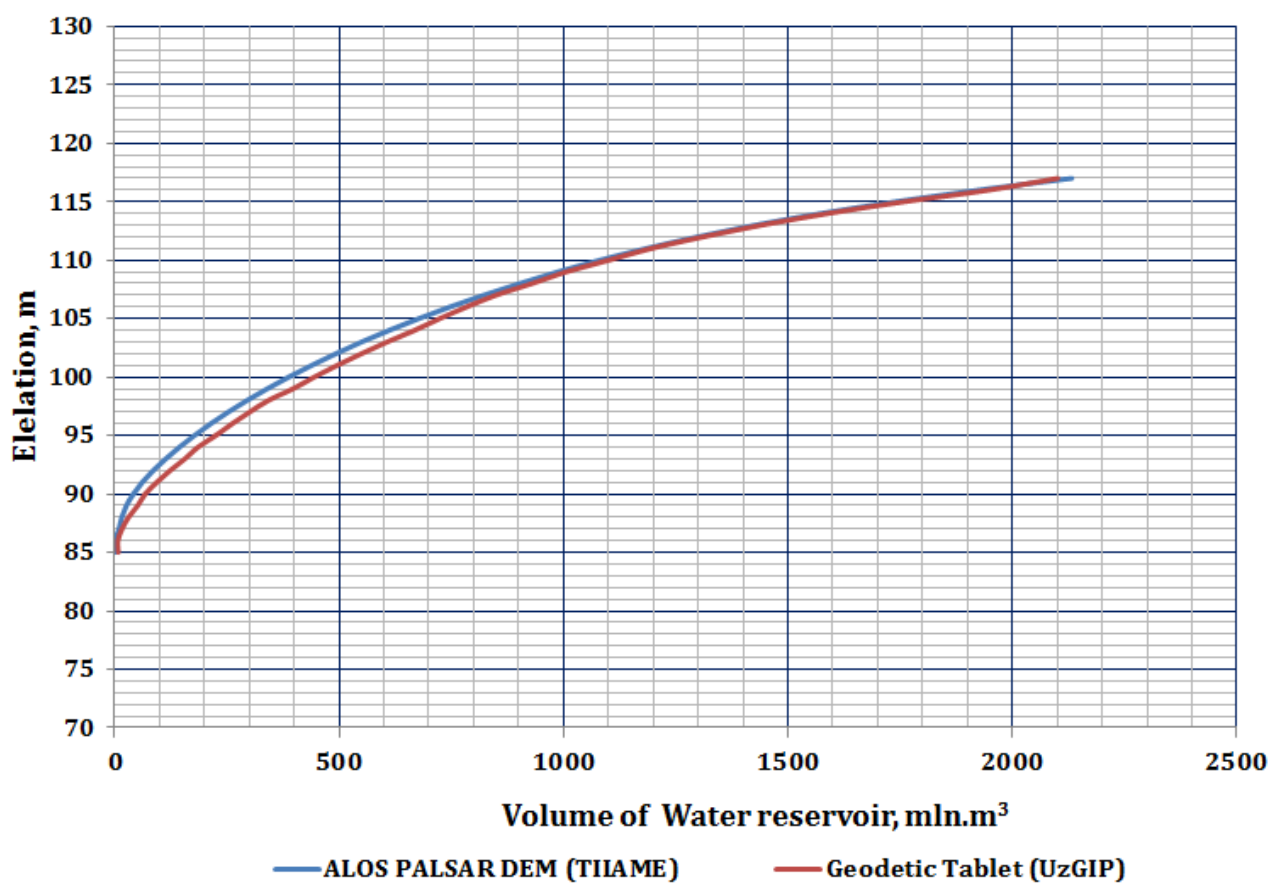

Figure 8: $\mathrm{F}=\mathrm{f}(\mathrm{H})$ Graphical relationship for water reservoir elevation and volume

\section{References}

Ayman, S. and Ling, H., 2019, Effects of Vertical Accuracy of Digital Elevation Model (DEM) Data on Automatic Lineaments Extraction from Shaded DEM. Advances in Space Research, Vol. 3(64) 603-622.
Barbarella, M., Fiani, M. and Zollo, C., 2017, Assessment of Dem Derived from Very 479 High-Resolution Stereo Satellite Imagery for Geomorphometric Analysis. European Journal of Remote Sensing, Vol. 50(1), 534-549 . 
Burrough, P. A. 1986, Principles of Geographical Information Systems for Land Resources Assessment (Monographs on Soil and Resources Survey No. 12) Oxford; Clarendon Press (Oxford University Press)

Chen, C. F., Liu, F. Y., Li, Y., Yan, C. and Liu, G., 2016, A Robust Interpolation Method for Constructing Digital Elevation Models from Remote Sensing Data. Geomorphology, Vol. 268, 275-287.

Chuanfa, Ch., Xin, W., Changqing, Y., Bin, G. and Guolin, L., 2016, A Total Error-Based Multiquadric Method for Surface Modeling of Digital Elevation Models, Journal GIScience \& Remote Sensing, Vol. 5(53), 578-595.

Cowan, D. and Cooper, G., 2005, Differential Reduction to the Pole, 67th EAGE Conference \& Exhibition, 3299-3302. DOI: https://doi.org/10.3997/2214-4609-pdb.1.H005.

Clewley, D., Whitcomb, J., Moghaddam, M., McDonald, K., Chapman, B. and Bunting, P., 2015, Evaluation of ALOS PALSAR Data for High-Resolution Mapping of Vegetated Wetlands in Alaska, Remote Sens., Vol. 7, 72727297

Milan, D. J., Heritage, G. L., Large, A. R. G. and Fuller, I. C., 2011, Filtering Spatial Error from DEMs: Implications for Morphological Change Estimation, Geomorphology, Vol. 1(125), 160171

Filatov, A., 2016, Application of ALOS\PALSAR Multi-Temporal Radar Acquisitions for Detection of Ground Displacements Under Arctic Conditions. Journal of Radio Electronics, Vol. 2, 1-18 (In Russian).

Fisher, P. F., 1996, Extending the Applicability of Viewsheds in Landscape Planning, Photogrammetric Engineering and Remote Sensing, Vol. 62, 297-302.

Hadrian, D. R., Bishop, I. D. and Mitcheltree, R., 1988, Automated Mapping of Visual Impacts in Utility Corridors, Landscape and Urban Planning, Vol. 16, 261-282.

Hensley, S., Rosen, P. and Gurrola, E., 2000, The SRTM Topographic Mapping Processor, International Geoscience and Remote Sensing Symposium, Vol. 3, 1168-1170.

James, T. D., Carbonneau, P. and Lane, S. N., 2007, Investigating the Effects of DEM Error in Scaling Analysis, Photogrammetric Engineering And Remote Sensing, Vol. 73 (1), 67-78.

Khasanov, Kh., 2020, Evaluation of ASTER DEM and SRTM DEM Data for Determining the Area and Volume of the Water Reservoir. IOP Conference Series Materials Science and
Engineering, 883 012063. DOI: 10.1088/1757899X/883/1/012063.

Khasanov, Kh., Bakiev, M., Choriev, J., Jahonov A. and Khalimbetov, A., 2019, Water Reservoir Area and Volume Determination Using Geoinformation Technologies and Remote Sensing, International Journal of Recent Technology and Engineering, Vol. 4(8) 54585461.

Komeil, R., Anuar, A. and Sharifeh, H., 2015, Comparative Analysis of ASTER DEM, ASTER GDEM, and SRTM DEM Based on GroundTruth GPS Data, Jurnal Teknologi, Vol. 76(1), 97-102.

Lei, F., Joel, S., Peter, A. and William, P., 2014, Propagation of Vertical and Horizontal Source Data Errors Into a TIN with Linear Interpolation, International Journal of Geographical Information Science, Vol. 7(28), 1378-1400.

Moritz, R. and Christian, H., 2014, Comparison of Free High Resolution Digital Elevation Data Sets (ASTER GDEM2, SRTM v2.1/v4.1) and Validation Against Accurate Heights from the Australian National Gravity Database, Australian Journal of Earth Sciences, 1-15.

Nelson, A., Reuter, H.I. and Gessler, P., 2009, DEM Production Methods and Sources, Developments in Soil Science, Vol. 33, 65-85.

Nikolakopoulos, K. G., Kamaratakis, E. K. and Chrysoulakis, N., 2006, SRTM vs ASTER Elevation Products. Comparison for Two Regions in Crete, Greece, International Journal of Remote Sensing, Vol. 27(21), 4819-4838.

Pierre, D., Douglas, J. K., Dikaso, G. U. and LisaMaria, R., 2017, Mapping the Dabus Wetlands, Ethiopia, Using Random Forest Classification of Landsat, PALSAR and Topographic Data, Remote Sens., Vol. 9(10), 1056.

Qiming, Zh. and Xuejun, L., 2004, Analysis of Errors of Derived Slope and Aspect Related to DEM Data Properties, Computers \& Geosciences, Vol. 4(30), 369-378.

Rabus, B., Eineder, M., Roth, A. and Bamler, R., 2003, The Shuttle Radar Topography Mission-A New Class of Digital Elevation Models Acquired by Spaceborne Radar, Journal of Photogrammetry and Remote Sensing, Vol. 4(57), 241-262.

Tachikawa, T., Kaku, M. and Iwasaki A., 2009, ASTER GDEM Validation. Presentation at the 35th ASTER Science Team Meeting, Kyoto, Japan.

Thomas, J., Prasannakumar, V. and Vineetha, P., 2015, Suitability of Spaceborne Digital Elevation Models of Different Scales in Topographic Analysis: An Example from 
Kerala, India, Environ. Earth Sci., Vol. 3 (73), 1245-1263.

Tom, G. F., Rosen, P. A., Caro, E., Crippen, R., Duren, R., Hensley, S., Kobrick, M., Paller, M., Rodriguez, E., Roth, L., Seal, D., Shaffer, S., Shimada, J., Umland, J., Werner, M., Oskin, M., Burbank, D. and Alsdorf, D., 2007, The Shuttle Radar Topography Mission, Reviews of Geophysics, Vol. 45, 1-33

Ugur, A., Baris, B. and Elif, S., 2018, Accuracy Assessment of Different Digital Surface Models, International Journal of Geo-Information, Vol. 7(3), 114-117.

Truong, V. T., Hoang, T. T., Cao, D. P., Hayashi, M., Tadono, T. and Nasahara, K. N., 2019, JAXA Annual Forest Cover Maps for Vietnam during 2015-2018 Using ALOS-2/PALSAR-2 and Auxiliary Data, Remote Sens., Vol. 11(20), 2412.

Wang, W., Yang, X. and Yao, T., 2012, Evaluation of ASTER GDEM and SRTM and their Suitability in Hydraulic Modelling of a Glacial Lake Outburst Flood in Southeast Tibet, Hydrological Processes, Vol. 26(2), 213-225.

Wasilewski, M. and Chormański, J., 2009, The Shuttle Radar Topography Mission Digital Elevation Model as an Alternative Data Source for Deriving Hydrological Characteristics In Lowland Catchment - Rogożynek catchment case study, Land Reclamation, Vol. 41(1), 7182.

Werner, M., 2001, Shuttle Radar Topography Mission (SRTM) Mission overview, Telecom. (Frequenz), Vol. 55, 75-79. 